\title{
Mechanisms underlying neutrophil adhesion to apical epithelial membranes
}

J Meenan, M Mevissen, H Monajemi, S A Radema, H R Soule, M Moyle, G N J Tytgat, S J H van Deventer interleukin $1 \beta$ (IL-1 $\beta$ ), IL-6, IL-8, tumour necrosis factor $\alpha(\mathrm{TNF} \alpha)$, leukotriene $\mathrm{B}_{4}$, platelet activating factor (PAF), proteases, and products of the respiratory burst reaction. ${ }^{2-4}$ Mucosal recruitment of neutrophils involves sequential adhesion and transmigration across endothelial, lamina propria and epithelial compartments. ${ }^{5}$ Subsequent adhesion to apical epithelial membranes results in activated neutrophils persisting in crypt abscesses with local release of chemotactic, chemoactivating, and, possibly, bactericidal substances. ${ }^{67}$ This localisation is of importance in the light of an increased translocation of luminal bacteria and their products associated with inflammatory bowel disease (IBD). ${ }^{8}$ Furthermore, the products of neutrophil localisation at epithelial surfaces may mediate mucosal leucocyte recruitment in IBD. ${ }^{9}$

Significant differences exist in the mechanisms employed by neutrophils to translocate across endothelial or epithelial cell layers. ${ }^{1011}$ Neutrophil recruitment from the circulation into the interstitium during inflammation is an extension of a physiological process across an adapted, permissive cell layer. Such transmigration involves the tethering, rolling, tight adhesion, and diapedesis of marginalised flowing cells. ${ }^{12}$ In contrast, the egress of neutrophils to form crypt abscesses occurs under static conditions, disrupts cellular tight junctions, and is independent of further migration. ${ }^{13}$ In addition, at the external epithelial surface both crypt architecture and intercellular adhesion are required to enable the continuing presence of crypt abscesses in the face of luminal flow and neutrophil mediated increase in fluid secretion. ${ }^{514}$

Neutrophil adhesion to the vascular endothelium as described in the 'traffic signal' paradigm, results from the sequential recruitment of selectins, $\beta_{2}$-integrins, tissue bound factors (IL-8, PAF) and products of the immunoglobulin gene superfamily. ${ }^{15}$ The relative contribution of these molecules depends on the degree of endothelial activation and on the stimulus employed. ${ }^{16}$ Similarly, cytokine activation of epithelial monolayers results in altered transmigration kinetics. ${ }^{17}$ Neutrophil $\beta 2$-integrin ligand preference varies between endothelial and epithelial cells. Although, intracellular adhesion molecule-1 (ICAM-1) (CD54) usage is not thought to be generally favoured with the latter, ${ }^{5}$ reports are inconsistent. ${ }^{18}$ Mucosal inflammation is associated with an increase in the expression of vascular and leucocyte adhesion molecules. ${ }^{1920}$ The importance of adhesive molecule expression on apical epithelial mem-
Correspondence to: Dr J Meenan, Department of Medical Centre, $1105 \mathrm{AZ}$ Amsterdam, the Netherlands.

Accepted for publication 15 August 1995
Vasodilation, oedema, leucocyte chemotaxis/ activation, and tissue destruction are features of acute inflammation. ${ }^{1}$ In acute colitis, activated neutrophils are the major effector cells of this inflammatory response, releasing 
branes is unclear and may not be the same as the processes described for adhesion related to chemotactic transmigration at the vascular endothelium or the basolateral epithelial membrane.

The relative significance of mediators of adhesion including selectins, $\beta_{2}$-integrins, PAF, and adenosine at the epithelial surface is unknown. This study aimed to examine the role of these mediators and to determine the efficacy of a novel inhibitor of CD11b/CD18 (Mac-1), recombinant neutrophil inhibitory factor (rNIF) in apical neutrophil-epithelial cell adhesion.

\section{Methods}

\section{ISOLATION OF NEUTROPHILS}

Venous blood from healthy volunteers, was drawn into tubes containing $3 \cdot 8 \%$ trisodium citrate. After mixing with an equal volume of Hanks's buffered salt solution (Life Technologies, Scotland) the blood was layered onto Ficoll-Hypaque (Pharmacia, Sweden) and centrifuged at $800 \mathrm{~g}\left(22^{\circ} \mathrm{C}\right)$ for 15 minutes. The erythrocyte/granulocyte pellet was resuspended in ice cold lysis buffer $\left(\mathrm{NH}_{4}\right.$ solution) and placed on ice. After an initial lysis, the cells were pelleted and resuspended in lysis buffer containing $0.2 \%$ human serum albumin (HSA). The granulocytes were washed twice in phosphate buffered saline containing $0 \cdot 2 \%$ HSA, brought to a concentration of $2.5 \times 10^{6}$ cells/ml in RPMI 1640 (Life Technologies) supplemented with $5 \%$ fetal bovine serum (Life Technologies) and kept at room temperature. Neutrophil preparations were of $>98 \%$ viability by eosin (Sigma, MO) exclusion.

\section{PREPARATION OF EPITHELIAL MONOLAYERS}

HT29 (clone 19A) colon carcinoma cells (passages 18-27), a kind gift from Professor C L Laboisse, ${ }^{21}$ were grown to confluency over 72 hours in 96-well culture plates (Costar, Cambridge, USA). The medium was changed 18 hours before each experiment. Stimulation of monolayers with interferon gamma (IFN $\gamma$ ) $100 \mathrm{U} / \mathrm{ml}$ (Boehringer Ingelheim) combined with TNF $\alpha 100 \mathrm{ng} / \mathrm{ml}$ (Chiron, USA) for 24 hours provided maximum neutrophil adhesion and upregulation of surface ICAM-1, as previously determined by flow cytometry (data not shown). In several studies epithelial cells were trypsinised (trypsin/EDTA, Life Technologies) and grown to confluency over 18 hours in the presence or absence of monensin $20 \mu M$ (Sigma), a protein translocation inhibitor, in order to examine the effect of extracellular matrix deposition on neutrophil adhesion.

\section{NEUTROPHIL CELL ADHESION ASSAYS}

Before stimulation with phorbol-myristateacetate (PMA) $100 \mathrm{ng} / \mathrm{ml}$ (Sigma), neutrophils were incubated with a panel of antibodies (Table) or regulatory agents including rNIF:200 nM, lexipafant (LFA-1) (PAF receptor antagonist): $1 \mathrm{ng}-10 \mu \mathrm{g} / \mathrm{ml}$; N6-cyclopentyladenosine (CPA):50-100 nM (Sigma) and $5^{\prime} \mathrm{N}$-ethylcarboxamidoadenosine (NECA): 10-50 nM (Sigma), adenosine receptor type $A_{1}$ and $A_{2}$ agonists respectively. In other experiments HT29 monolayers were pretreated $\left(10 \mathrm{~min} / 37^{\circ} \mathrm{C}\right)$ with aICAM-1A, lexipafant: $1 \mathrm{ng}-10 \mu \mathrm{g} / \mathrm{ml}$, aE-selectin or aP-selectin. In all experiments, neutrophils were added to the apical epithelial surface in a ratio of $2: 1$ and incubated under static conditions for 30 minutes at $37^{\circ} \mathrm{C}$. Test agents were present throughout this period. Antibodies were used at a previously determined optimal concentration of $10 \mu \mathrm{g} / \mathrm{ml}$. rNIF, aCD18/aICAM-1A, aE-selectin/aPselectin, and lexipafant were kind gifts of Dr H Soule, Corvas Corporation, San Diego; Dr $\mathrm{R}$ Rothlein, Boehringer Ingelheim, Massachusetts; Dr J Woody, Centocor, Pennsylvania; and Dr M Wood, British Biotechnology, Oxford respectively. BCA1, BCA2, and BBA4 were purchased from $R \& D$ Systems, Minneapolis, B2.12 was a kind gift of the Red Cross Laboratory for Blood Transfusions (CLB), Amsterdam.

After incubation, culture plates were washed three times in warmed PBS to remove nonadherent neutrophils. HT29 monolayers were detached by incubating with $1 \mathrm{mM}$ EDTA/ trypsin (Life Technologies), hexadecyltrimethylammonium bromide (HTAB) 1\% was added and plates were freeze-thawed three times in order to free cellular myeloperoxidase (MPO). ${ }^{22}$ Neutrophil adhesion was quantified by adding o-phenylenediamine dihydrochloride (Sigma) with $0.005 \% \mathrm{H}_{2} \mathrm{O}_{2}$ in citrate buffer (pH5) and the optical densities of the plates determined at $490 \mathrm{~nm}$ (Thermomax, Molecular Devices). The MPO activity of samples was compared with that of known numbers of neutrophils from the same donor. HT29 cells consistently failed to show MPO activity. Varying concentrations of PMA (0, $25,50,100 \mathrm{ng} / \mathrm{ml}$ ) had no effect on measurable MPO activity. Intra-assay and interassay coefficients of variation were consistently $<5 \%$.

\section{STATISTICS}

Statistical analysis was performed using SPSS for Windows 6.0 (SPSS Inc, USA). Data are expressed as number of neutrophils $\left(\times 10^{3}\right)$ (SEM). In general, the data presented are cumulative from at least three experiments. The total number of wells used are given. ICAM-2 was tested in one experiment only, using 10 wells. Differences between groups

Monoclonal antibodies used in adhesion experiments

\begin{tabular}{ll}
\hline Agent & Clone/antibody \\
\hline aCD18 & R15·7 \\
aCD11b mix & B2·12 and BCA2 \\
aICAM-1A (CD54) & R6.5 \\
aICAM-1B (CD54) & BBA4 \\
aICAM-2 (CD102) & 5D6 \\
aLFA-1 (CD11a/CD18) & BCA1 \\
aE-selectin (CD62E) & C197 \\
aP-selectin (CD62P) & C174 \\
\hline
\end{tabular}




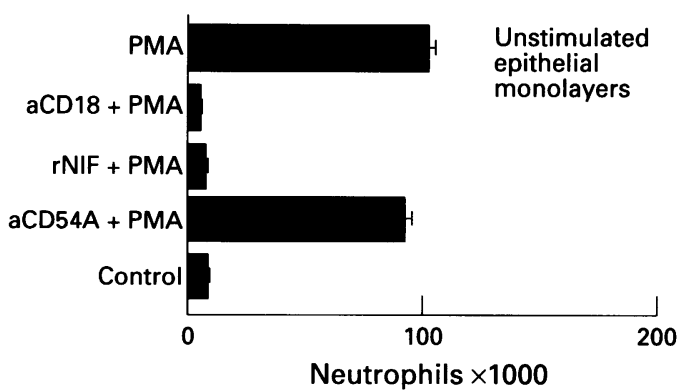

Figure 1: Neutrophil adhesion to resting HT29 monolayers in the presence of: phorbolmyristate-acetate (PMA), aCD18, intracellular adhesion molecule $1 A$ (aICAM-1A $(C D 54 A))$ or neutrophil inhibitory factor ( $r N I F)$ Control=unstimulated neutrophils.

were calculated using Student's $t$ test. Alpha was set at $0 \cdot 05$.

\section{Results}

HT29 cell monolayers grown to confluency over 72 hours, when incubated with PMA activated neutrophils, demonstrated an increase in adhesion (103(3), $n=50,41 \%$ of added cells) compared with values seen with unstimulated neutrophils $(8 \cdot 7(0 \cdot 7), \mathrm{n}=95$, $\mathrm{p}<0.001)$. Incubation with aCD18 and rNIF, in addition to PMA, reduced neutrophil adhesion to $5 \cdot 7(0 \cdot 3)(\mathrm{n}=47, \mathrm{p}<0 \cdot 001)$ and $8 \cdot 1(0 \cdot 7)$ $(\mathrm{n}=39, \mathrm{p}<0.001)$ respectively. aCD18 mediated a reduction in stimulated neutrophil adhesion to below that of unstimulated neutrophils $(p<0.01)$ (Fig 1). Pre-incubation of neutrophils/epithelial monolayers with aICAM-1A (93(3), $n=49)$, lexipafant (120(11), $n=19)$, aE-selectin (95(2), $n=13)$, or aP-selectin (110(3), $n=13)$ did not alter stimulated neutrophil adhesion significantly.

Incubation of unstimulated neutrophils with either CPA (50 nM:8.2(0.2); $100 \mathrm{nM}$ : $8 \cdot 6(0 \cdot 2)$, or NECA $(10 \mathrm{nM}: 7 \cdot 9(0 \cdot 2) ; 50 \mathrm{nM}$ : $7 \cdot 6(0 \cdot 2)$ failed to influence adhesion significantly.

Stimulation of HT29 monolayers with IFN $\gamma / \mathrm{TNF} \alpha$ resulted in increased adhesion of both unstimulated $(15 \cdot 7(0.9), n=32$, $\mathrm{p}<0.001)$ and PMA stimulated (139(9), $\mathrm{n}=16, \mathrm{p}<0,01)$ neutrophils when compared with resting monolayers. The addition of aCD18 to stimulated neutrophils once again reduced binding $(8 \cdot 5(0 \cdot 4), \mathrm{n}=48, \mathrm{p}<0 \cdot 001)$, though it did not abolish the cytokine induced

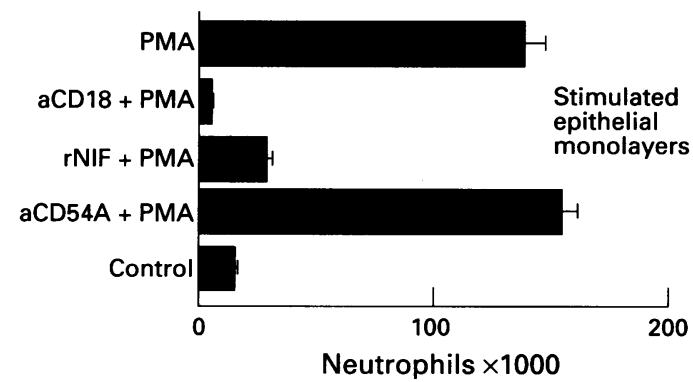

Figure 2: Neutrophil adhesion to cytokine stimulated HT29 monolayers (interferon gamma/tumour necrosis factor $\alpha$ (IFN $\gamma / T N F \alpha)$ ) in the presence of: phorbol-myristateacetate (PMA), neutrophil inhibitory factor ( $r N I F)$, or monoclonal antibodies: aCD18, intracellular adhesion molecule $1 A$ (aICAM-1A (CD54A)).

Control=unstimulated neutrophils.

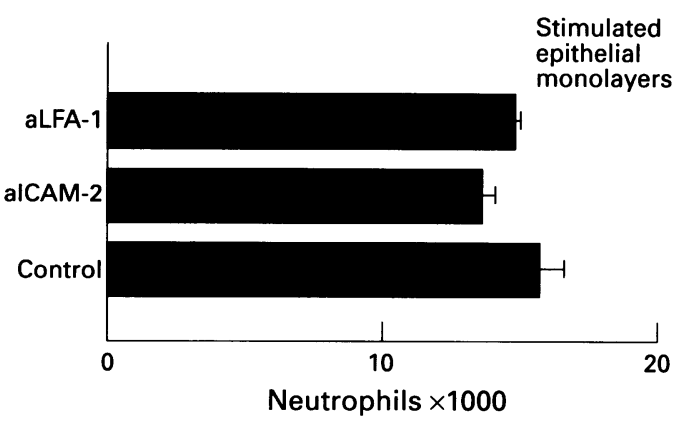

Figure 3: Resting neutrophil adhesion to cytokine stimulated HT29 monolayers in the presence of monoclonal antibodies against LFA-1, or intracellular adhesion molecule-2 (ICAM-2). Control=unstimulated neutrophils.

effect completely. rNIF had a similar, though less potent effect $(29 \cdot 4(1 \cdot 6), n=33)$. Once again, aICAM-1A failed to block stimulated neutrophil adhesion (155(6.4), $n=8$ ) (Fig 2). aLFA-1 showed no effect on neutrophil adhesion $(14 \cdot 8(0 \cdot 2), \mathrm{n}=16)$. ICAM-2 did not block neutrophil adhesion $(13 \cdot 6(0 \cdot 5) v 14(0 \cdot 3)$ (Fig 3).

A further adhesion assay was performed to compare the efficacy of rNIF and aCD18 with (a) a mixture of aCD11b monoclonal antibodies and (b) a combination of rNIF, aCD11b mix, and aLFA-1. To confirm the lack of effect of aICAM-1 blockade another neutralising antibody was used, aICAM-1B. The results are presented in Fig 4 .

Adhesion of unstimulated neutrophils to HT29 monolayers grown to confluency over 18 hours was high $(85(4), n=24)$, though it was inhibited by adding monensin to cultures at the time of epithelial cell plating (47(9), $\mathrm{n}=24, \mathrm{p}<0.001)$. aCD18 and rNIF combined did not block this adhesion (89(10), $n=8)$. Higher concentrations of monensin led to poor HT29 cell adhesion to culture plates, rendering monolayers unsuitable for neutrophil adhesion assay.

\section{Discussion}

The apical membrane of polarised epithelial cells is an important site for the interaction between luminal contents and mucosa. ${ }^{23}$ The formation and persistence of neutrophil aggregates in the colonic crypts is a feature of both

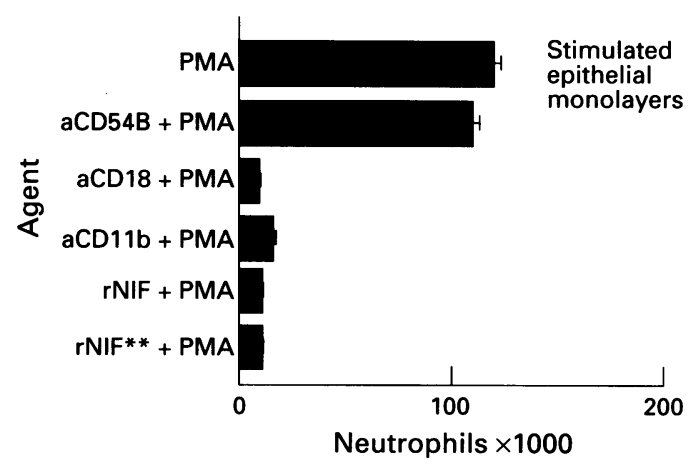

Figure 4: Activated neutrophil (phorbol-myristate-acetate $(P M A)$ ) adhesion to cytokine stimulated (IFN $\gamma / T N F \alpha)$ ) HT29 monolayers in the presence of aCD18, aICAM-1B (CD54B), aCD11b mix, neutrophil inhibitory factor ( $r N I F)$ alone or $r N I F$ combined with $a C D 11 b$ mix and rNIF aLFA-1 (NIF**). 
inflammatory bowel disease (ulcerative colitis, Crohn's disease) and of infectious colitis, contributing to observed clinical features. ${ }^{124}$ Retention of activated neutrophils at this site results in the local release of inflammatory mediators and increased luminal chloride secretion. ${ }^{5}$ The relative influences of shear force, chemotactic stimuli, and polarised antigen expression, distinguishes conditions at endothelial and basolateral epithelial membranes from those in the crypt lumen. Consequently, to mimic these conditions in vitro, we have employed a static model, using a differentiated epithelial cell line that demonstrates polarity both in structure and in response to stimuli. ${ }^{21} 25$

Neutrophil adhesion (both stimulated and unstimulated) to the apical epithelial membrane (resting and cytokine activated) was shown to be CD18 and CD11b dependent, but independent of ICAM-1. These findings are similar to those reported for transmigration related adhesion to epithelium in studies utilising the chemotactic agent fMLP. ${ }^{10}$ Similar ligand utilisation has also been noted at the bronchus, despite relatively high constitutive expression of ICAM-1. ${ }^{26} 27$ The ligand for CD11b/CD18 (Mac-1) on the epithelial cell is not yet known. It is unlikely to be ICAM-2 as we have shown that neutralising this molecule does not influence unstimulated neutrophil adhesion to an activated epithelial monolayer. The restricted distribution of ICAM-2 to leucocytes and endothelial cells supports this hypothesis. ${ }^{28}$ Similarly, ICAM-3 is an unlikely target ligand as its expression is limited to leucocytes. ICAM-3 is associated with lymphocyte adhesion and activation ${ }^{29}$ and is unlikely to play a role in neutrophil adhesion. It cannot be discounted that the inability of the aICAM-1 antibodies to neutralise adhesion was caused by variant ICAM-1 epitope expression by the cell line under study.

Neutrophil inhibitory factor is a novel glycoprotein from the canine hookworm that binds to the I domain of CD11b/CD18 and inhibits neutrophil function including adhesion. ${ }^{30} 31$ Recombinant NIF has been shown to inhibit neutrophil adhesion and transmigration through endothelial monolayers. ${ }^{32}$ This study shows that rNIF has similar inhibitory properties at the epithelial surface. The disparity in effect between rNIF and a mixture of characterised CD11b neutralising antibodies is similar to that effect seen with endothelial monolayers and highlights the contribution of particular adhesion molecule epitopes to specific functions. The demonstrated lack of efficacy of E-selectin and P-selectin blockade is consistent with the limited distribution of these molecules and emphasises differences in mechanisms of neutrophil adhesion between endothelial and epithelial cells. ${ }^{33}$

Mucosal inflammation is associated with recruitment of leucocytes, synthesis and release of cytokines, and the up-regulation of adhesion molecules. ${ }^{192034}$ Stimulation of epithelial monolayers with IFN $\gamma / T N F \alpha$, resulted in increased adhesion both of stimulated and unstimulated neutrophils. We observed this process to be CD18 dependent and ICAM-1 independent. However, the relative contribution of $\mathrm{CD} 11 \mathrm{~b} / \mathrm{CD} 18$ seems to be diminished, and neutralising CD18 does not return adhesion to those levels seen with unstimulated epithelial cells. Increased adhesion of unstimulated neutrophils to recently trypsinised epithelial cells (18 hour group) was not blocked by aCD18 or rNIF. These findings suggest that distinct and as yet unidentified epithelial cell adhesion molecules might be involved in the binding of neutrophils under these conditions. Interruption of epithelial cell protein translocation by treatment of the HT29 cell monolayer with monensin partially prevented the increase in neutrophil adhesion. This suggests that the ligands present on the epithelial membrane are not structural molecules and are dissimilar to those utilised by epithelial cells for adherence in culture. In a supplementary experiment (data not shown) we incubated recently trypsinised cells with sodium heparin to block surface heparin binding chemokines, as described for studies with monocytes ${ }^{35}$ - to no effect.

The physiological effects of adenosine and the pro-inflammatory membrane phospholipad metabolite PAF are well recognised. ${ }^{36-38}$ Neutrophil adhesion to endothelium is enhanced by activation of adenosine $A_{1}$ receptors. Binding to the $A_{2}$ receptor results in inhibition of the respiratory burst reaction and decreased binding to fibrinogen. ${ }^{39}$ Furthermore, neutrophil mediated induction of colonocyte adenosine synthesis is a feature of neutrophil-epithelial interaction. ${ }^{5}$ Incubation of both neutrophils and epithelial monolayers with CPA $\left(A_{1}\right)$ or NECA $\left(A_{2}\right)$, failed to influence neutrophil adhesion. Whether adenosine released or formed at the apical epithelial membrane has a cytoprotective function impairing neutrophil oxidative burst, in addition to mediating fluid outflow, is unknown. The lack of efficacy of lexipafant in this study suggests that an autocrine effect by PAF on stimulated neutrophils does not influence adhesion to epithelium significantly. It cannot be excluded that any potential stimulatory action of epithelial PAF is surpassed by that of PMA.

In conclusion, retention of activated neutrophils at the external epithelial surface alters membrane function and maintains a chemotactic gradient across the mucosa. The mechanisms underlying this process are distinct from those described at the vascular endothelium. Our model suggests that neutrophilapical membrane adhesion is CD11b/CD18 dependent with ICAM-1, ICAM-2, PAF, E-selectin, P-selectin and adenosine contributing little.

1 Domizio P. Pathology of chronic inflammatory bowel disease in children. In: Walker-Smith JA, MacDonald disease in children. In: Walker-Smith JA, MacDonald London: Bailliere Tindall 1994; 35-64.

2 Hayllar J, Bjarnason I. Sulphasalazine in ulcerative colitis. Gut 1991; 32: 462-3.

3 Roos D, Dolman K. Neutrophil involvement in inflammatory tissue damage. Netherlands $\mathcal{F}$ Med 1990; 36: 89-94

4 McColl SR, Showell HJ. Neutrophil derived inflammatory mediators. In: Hellewell PG, Williams TJ, eds. Immunopharmacology of neutrophils. London: Academic Press 1994; 95-114. 
5 Madara JL. Migration of neutrophils through epithelial monolayers. Trends in Cell Biology 1994; 4: 4-7.

6 Nathan CF. Neutrophil activation on biological surfaces: massive secretion of hydrogen peroxide in response to massive secretion of hydrogen peroxide in response to products of macrop

7 Opal SM, Palardy JE, Marra MN, Fisher CJ, McKelligon BM, Scott RW. Relative concentrations of endotoxin binding proteins in body fluids during infection. Lance 1994; 344: 429-31.

8 van Deventer $\mathrm{SJH}$, ten Cate JW, Tytgat GNJ. Intestinal endotoxaemia: clinical significance. Gastroenterology 1988; 94: 825-31.

9 Teahon K, Bjarnasson I. Comparison of leukocyte excretion and blood loss in inflammatory disease of the bowel. Gut 1993; 34: 1533-8.

10 Parkos CA, Delp C, Araout MA, Madara JL. Neutrophil migration across a cultured intestinal epithelium: depenmigration across a cultured intestinal epithelium: depenefficiency in physiological direction. $\mathcal{f}$ Clin Invest 1991; 88: $1605-12$.

11 Kuijpers TW, Hakkert BC, van Mourik JA, Roos D Distinct adhesive properties of granulocytes and monocytes to endothelial cells under static and stirred conditions. F Immunol 1990; 145: 2588-94.

12 Adams DH, Shaw S. Leucocyte-endothelial interactions and regulation of leucocyte migration. Lancet 1994; 343 831-6.

13 Nash S, Stafford J, Madara JL. Effects of polymorphonuclear leucocyte transmigration on the barrier function of cultured intestinal epithelial monolayers. $\mathcal{F}$ Clin Invest 1987; 80: 1104-13.

14 Madara JL, Patapoff TW, Gillece-Castro P, Colgan SP parkos CA, Delp C, Mrsny RJ. 5'-adenosine monophosphate is the neutrophil derived paracrine factor that elicits chloride secretion from T84 intestinal ep
monolayers. F Clin Invest 1993; 91: 1857-58.

15 Springer TA. Traffic signals for lymphocyte recirulation and leukocyte emigration: the multi-step paradigm. Cell 1994 76: 301-14.

16 Kuijpers TW, Hakkert BD, Hart MHL, Roos D. Neutrophil migration oacross monlayers of cytokine prestimulated endothelial cells: a role for PAF and IL-8. fCell Biol 1992; 117: 565-72.

17 Colgan SP, Parkos CA, Delp C, Arnaout MA, Madara JL Neutrophil migration across cultured intestinal epithelial monolayers is modulated by epithelial exposure to IFN monolayers is modulated by epithelial exposure to 1 . gamma

18 Kelly CP, Keates S, Siegenberg D, Linevsky JE, Pothoulakis C, Brady HR. IL-8 secretion and neutrophil activation by HT-29 colonic epithelial cells. Am $\mathcal{F}$ Physiol 1994; 267: G991-7.

19 Balsitis M, Morrell K, Mahida Y, Hawkey CJ. Cell adhesion molecule expression by colonic mucosa in ulcerative colitis. Eur f Gastroenterol Hepatol 1994; 6: 351-8.

20 Dippold W, Wittig B. Schwaeble W, Mayet W, Meyer zum Buschenfelde. Expression of intercellular adhesion molecule 1 (ICAM-1, CD54) in colonic epithelial cells. molecule 1 (ICAM-1,

21 Augeron C, Laboisse CL. Emergence of permanently differentiated cell clones in a human colonic cancer cell line in entiated cell clones in a human colonic cancer cell line in culture after treatme

22 Grisham MB, Bennoit JN, Granger DN. Assessment of leukocyte involvement during ischemia and reperfusion of intestine. Methods Enzymol 1990; 186: 729-42.

23 Wick MJ, Madara JL, Fields BN, Normark SJ. Molecular cross talk between epithelial cells and pathogenic microorganisms. Cell 1991; 67: 651-9.

24 Kelly CP, Becker S, Linevsky JK, Joshi MA, O'Keane JC, Dickey BF, LaMont JL, Pothoulakis C. Neutrophil recruitment in Clostridium difficile toxin $\mathrm{A}$ enteritis in the rabbit. F Clin Invest 1994; 93: 1257-65.

25 Lammers KM, Jansen J, Bijlsma P, Ceska M, Tytgat GM, Laboisse CL, van Deventer SJH. Polarized interleukin-8 secretion by HT29/19A cells. Gut 1994; 35: 338-42.

26 Stark JM, Smith CW, Gruenert DC, Tosi MF. Neutrophil adhesion to para-influenza virus infected human airway epithelial cells. Possible contributions of ICAM-1 dependent and ICAM-1 independent mechanisms. Chest 1992; 101: 40s-41s.

27 Tosi MF, Hamedani A, Brosovich J, Alpert SE. ICAM-1 independent, CD18 dependent adhesion between neutrophils and human airway epithelial cells exposed in vitro to ozone. F Immunol 1994; 152: 1935-42.

28 deFougerolles AR, Stacker SA, Schwarting R, Springer TA Characterization of ICAM-2 and evidence for a third counter receptor for LFA-1. F Exp Med 1991; 174: 253-63.

29 Gorski $A$. The role of cell adhesion molecules in immunopathology. Immunol Today 1994; 15: 251-5.

30 Muchowski PJ, Zhang L, Chang ER, Soule HR, Plow EF, Moyle M. Functional interaction between the integrin antagonist neutrophil inhibitory factor and the I domain of CD11b/CD18. F Biol Chem 1994; 269: 24 419-23.

31 Rieu L, Ueda T, Haruta I, Sharma CP, Arnaout MA. The A-domain of $\beta_{2}$ integrin CR3 (CD11b/CD18) is a receptor for the hookworm derived neutrophil adhesion receptor for the hookworm derived neutrophil

32 Mevissen M, Meenan J, Soule HR, Moyle M, Buller HR van Deventer SJH. Inhibition of neutrophil migration across and adherence to monoloyers of endothelial cells by neutrophil inhibitory factor (rNIF). Proceedings XIV Cardiovascular Disease International Symposium, Washington, 1994.

33 Wardlaw AJ, Walsh GM. Neutrophil adhesion receptors. In: Hellewell PG, Williams TJ, eds. Immunopharmacology of neutrophils. London: Academic Press 1994; 133-57.

34 Sartor RB. Cytokines in intestinal inflammation: pathophysiological and clinical considerations. Gastroenterology 1994; 106: 533-9.

35 Schwartz D, Andalibi A, Chaverri-Almada L, Berliner JA Kirchgessner T, Fang ZT, et al. Role of the GRO family of Kirchgessner T, Fang ZT, et al. Role of the GRO family of chemokines in monocyte adhesion to MM-LDL stim

36 Prescott SM, Zimmerman GA, McIntyre TM. Platelet activating factor. F Biol Chem 1990; 265: $17381-4$

37 Bouma MG, Stad RK, van den Wildenberg FAJM Buurman WA. Differential regulatory effects of adenosine on cytokine release by activated human monocytes. I Immunology 1994; 153: 4159-68.

38 Dianzani C, Brunelleschi S, Viano I, Fantozzi R. Adenosine modulation of primed human neutrophils. Eur $\mathcal{f}$ Pharmacol 1994; 263: 223-6.

39 Cronstein BN, 263: 223-6. Philips $M$, Hirschhorn $R$ Abramson SB, Weissman G. Neutrophil adherence to
endothelium is enhanced via adenosine Al receptors and inhibited via adenosine A2 receptors. F Immunol 1992; 148: 2201-6. 